\title{
Politique
}

Politique

\section{Louis Massicotte et André Bernard, Le scrutin au Québec : un miroir déformant, Montréal, HMH, 1985, 255 p.}

\section{André Blais}

Numéro 10, automne 1986

Opinions et votes

URI : https://id.erudit.org/iderudit/040536ar

DOI : https://doi.org/10.7202/040536ar

Aller au sommaire du numéro

Éditeur(s)

Société québécoise de science politique

ISSN

0711-608X (imprimé)

1918-6584 (numérique)

Découvrir la revue

Citer ce compte rendu

Blais, A. (1986). Compte rendu de [Louis Massicotte et André Bernard, Le scrutin au Québec : un miroir déformant, Montréal, HMH, 1985, 255 p.] Politique, (10), 119-122. https://doi.org/10.7202/040536ar

Ce document est protégé par la loi sur le droit d'auteur. L'utilisation des services d'Érudit (y compris la reproduction) est assujettie à sa politique d'utilisation que vous pouvez consulter en ligne.

https://apropos.erudit.org/fr/usagers/politique-dutilisation/
Cet article est diffusé et préservé par Érudit.

Érudit est un consortium interuniversitaire sans but lucratif composé de l’Université de Montréal, l'Université Laval et l'Université du Québec à Montréal. Il a pour mission la promotion et la valorisation de la recherche. https://www.erudit.org/fr/ 
RECENSIONS

Louis Massicotte et André Bernard, Le scrutin au Québec: un miroir déformant, Montréal, HMH, 1985, 255 p.

L'ouvrage réalise la synthèse de deux textes: la thèse de doctorat d'André Bernard, complétée en 1969, et la thèse de maitrise de Louis Massicotte, soumise en 1979. Il présente une analyse des inégalités de représentation dans le cas des élections à l'Assemblée nationale et des efforts entrepris pour les réduire. La thèse principale est à l'effet 'que "les réformes réalisées jusqu'ici ont récemment mené à une réduction des inégalités dites structurelles, et à l'effacement croissant des intérêts partisans dans la délimitation des frontières des circonscriptions, alors même qu'elles étaient sans effet sur les inégalités dites conjoncturelles ou mécaniques qui découlent principalement du mode de scrutin introduit au Québec en 1792 et conservé depuis». (p. 6)

Les auteurs distinguent trois types d'inégalités; celles numériques, qui renvoient à la répartition numérique entre circonscriptions électorales, celles incidentes, qui tiennent à la concentration ou dispersion territoriale de certaines catégories d'électeurs, et celles mécaniques, découlant du mode de scrutin. Un premier chapitre présente une vue d'ensemble des trois types d'inégalités.

Il y est démontré que les inégalités mécaniques sont les plus importantes. Un deuxième chapitre fait un survol des réformes de la carte électorale. On y montre en particulier que le gerrymandering, même silencieux (c'est-à-dire ne pas diviser des districts populeux favorables à l'opposition et ne pas réunir des districts peu populeux favorables au gouvernement), n'a pas été une pratique courante. Suivent six chapitres sur les réformes proposées, débattues 
et mises en application, au cours de différentes périodes (1867$1960,1960-1970,1970-1972,1972-1981,1981-1984)$ et un dernier, portant spécifiquement sur les conséquences du mode de scrutin sur les électeurs de langue anglaise.

Le livre est utile et intéressant à plusieurs égards. Il est bien écrit et les différentes mesures de l'inégalité de représentation sont présentées de façon claire et simple. Il contient des informations factuelles précieuses sur les réformes, les objectifs visés et les effets réels, ainsi que les débats qui les ont entourées. La thèse principale qui est avancée, c'est-à-dire l'effet déterminant du mode de scrutin, est bien démontrée. Le livre se termine de plus sur une observation fort pertinente (même si peu exploitée):

«Ainsi le comportement des élites politiques québécoises sur la réforme du mode
de scrutin ébranle-t-il les généralisations théoriques postulant que les partis, en
tant qu'acteurs rationnels, procéderont en cette matière à tous les changements
leur permettant d'améliorer leurs positions ou de préconiser leur avantage.... A
la froide réalité qu'elles postulent chez les acteurs politiques, il faudra greffer une
certaine dose d'idéalisme de conservatisme foncier et même d'aveuglement pur et
simple afin de rendre compte de toute la complexité des facteurs en jeu». (p. 241).

L'ouvrage comporte par contre un certain nombre de faiblesses. C'est ainsi qu'on comprend mal le soin que les auteurs prennent à décrire parfois dans le détail les refonte de la carte électorale quand ils prétendent par ailleurs (avec raison) que la carte est beaucoup moins importante que le mode de scrutin. Mais c'est davantage au niveau des présupposés théoriques que le problème le plus sérieux se pose.

D'une part, le titre du livre laisse croire que le mode de scrutin peut n'être qu'un reflet des préférences des électeurs (p. 233). On devine d'ailleurs que ce miroir fidèle, ce serait le système proportionnel. Mais, comme l'a souligné Riker (1984), il ne saurait y avoir de système neutre puisque les préférences des électeurs et les stratégies des partis sont elles-mêmes dépendantes (en partie) du mode de scrutin; c'est ce que Lemieux, Gilbert et 
Blais (1970) ont appelé les effets en amont du mode de scrutin. Malheureusement, ces effets ne sont pas traités dans l'étude.

D'autre part, et ce point est plus important, les auteurs ne discutent guère leur critère de référence pour ce qui est de l'appréciation des distorsions du mode de scrutin qui est la représentation des partis à l'Assemblée nationale. Or, on pourrait fort bien imaginer d'autres critères. Par leur vote, les électeurs expriment également leurs préférences pour des individus (candidats locaux et chefs de partis) et les distorsions du scrutin majoritaire sont peut être moindres que celles du scrutin proportionnel à cet égard. Même en demeurant dans une perspective partisane, on pourrait également penser, à la suite de Taylor (1984) et de Taylor et Lijphart (1985) que c'est en fonction de la représentation au gouvernement sur un certain nombre d'années qu'il faut évaluer les modes de scrutin et de ce point de vue le système majoritaire n'a rien à envier au système proportionnel.

En somme, les auteurs démontrent bien que le scrutin majoritaire au Québec est un miroir déformant et qu'il est plus déformant que le système proportionnel par rapport au type de représentation retenu, mais il faudrait ajouter qu'il est moins déformant par rapport à d'autres critères de représentation. De ce point de vue, les débats les plus récents sur le mode de scrutin, au plan international (Lijphart et Grofman, 1984) n'ont guère de résonnance ici.

Les tenants du scrutin proportionnel sont portés à imputer le maintien d'un système majoritaire déformant au fait que «le Québec se situe dans une zone culturelle et géographique peu favorable à la remise en question des institutions» (p. 238). Mais il faudrait bien dire que l'inertie institutionnelle joue dans les deux sens. L'histoire des démocraties nous apprend qu'il est plus facile de passer du système majoritaire au système proportionnel que l'inverse. D'ailleurs comme l'étude le montre, le scrutin proportionnel est bien préférable pour le politicien qui désire 
conserver son poste. Alors conviendrait-il de remercier les politiciens québécois de ne pas penser exclusivement en fonction de leurs intérêts à court terme?

\section{André Blais}

\section{Université de Montréal}

1. Vincent Lemieux, Marcel Gilbert et André Blais, Une élection de réalignement : l'élection générale du 29 avril 1970 au Québec. (Montréal, Éditions du Jour, 1970).

2. Arend Lijphart et Bernard Grofman, "Choosing an Electoral System» dans Arend Lijphart et Bernard Grofman (dir.). Choosing an Elec toral System: Issues and Alternativese. (New-York, Praeger, 1984).

3. William H. Riker. «Electoral Systems and Constitutional Restraints» Dans Arend Lijphart et Bernard Grofman (dir.). Choosing an Electoral System: Issues and Alternatives. (New-York, Praeger, 1984).

4. Peter J. Taylor. «The Case for Proportional Tenure: A Defense of the British Electoral System" dans Arend Lijphart et Bernard Grofman (dir.). Choosing an Electoral System: Issues and Alternatives. (New-York, Praeger, 1984).

5. Peter J. Taylor et Arend Lijphart, «Proportional Tenure is Proportional Representation: Introducing a New Debate». European Journal of Political Research 13 (déc. 1985): 387-399. 